\title{
luxury shopping tourism: views from Chinese post-90s female tourists
}

\begin{abstract}
Purpose: The study explores how the concept of the extended self influences luxury shopping tourism consumption among Chinese tourists. It explores why luxury shopping is important for Chinese tourists. Specifically, this study focuses on a strategically important emerging market segment: post-90s female Chinese tourists.
\end{abstract}

Design: To explore the link between the extended self and luxury shopping tourism consumption among post-90s Chinese female tourists, this study adopted a qualitative and interpretive approach. 22 Semi-structured in-depth interviews were carried out to collect the data.

Findings: This qualitative inquiry found that luxury shopping during overseas holidays has some subtle differences from luxury shopping in China, as the conceptualisation of luxury is highly context-based. Through a focus on gender and generational differences, the current study reveals that the idea of individuality has started to influence their luxury purchases.

Practical implication: The study shows how different selves are associated with luxury shopping. It thus provides empirical evidence regarding the reasons behind their motivation, especially for shopping overseas in order to get a good price, and an exclusive and enjoyable luxury shopping experience abroad. Also, it was found that curiosity about buying luxury products is viewed as less favoured and logical shopping will be a future trend. Individuality is becoming a trend for younger consumers.

Originality: Theoretically, by linking the "extended self" with luxury shopping tourism, this study aims to understand the social-psychological aspects of luxury shopping tourism. Instead of focusing on particular destinations, the study provides compressed but also focused inquiries to explore how the concept of the self influences post-90s female Chinese tourists' shopping consumption while on holiday and how this luxury shopping experience influences their concept of the self.

\section{INTRODUCTION}

In recent years, Chinese tourists have frequently been named the most profitable market for destinations due to their high spending power and growing potential. In 2018, mainland Chinese made 130.51 million outbound trips, a $10 \%$ growth rate compared with 2018 (Travel Weekly China, 2019). Destination marketers and organisations are therefore eager to learn ways of attracting Chinese tourists and making them spend more in destinations. Among those studies, Chinese tourist behaviour has become a well-studied topic (Li \& Lu, 2016). Also, shopping behaviour is becoming a priority, but most studies have not explored the meaning attached to shopping to provide a deep understanding of tourists' rational and motivation for shopping (Correia, Kozak, \& Kim , 2018; Jin, Moscardo, \& Murphy , 2017), especially in regard to luxury shopping (Hung, Zhangg, Guillet, \& Wang, 2018).

Much of the existing research highlights that materialism, and the desire for status and to conform with others, motivate Chinese tourists' intention to purchase luxury goods 
and services while on holiday (e.g., Correia et al., 2018; Hung et al., 2018). Shopping has become an extremely important component of Chinese tourists' overseas holidays. Research has found that compared with the Japanese, who prefer luxury shopping at home, the majority of the Chinese prefer luxury shopping overseas and are willing to spend three times more during their holidays (Bain \& Company, 2017). While many studies have focused on shopping tourism, this subtle difference between shopping at home and at destinations needs further investigation (Hung et al., 2018). As a result, we are still not sure why shopping is important for Chinese tourists, especially during overseas holidays.

The lack of a theoretical foundation is a notable problem within the research on tourists' shopping habits. A review of the published work on tourist shopping revealed that Jin et al. (2017) found that consumer research concepts such as satisfaction and customers' perceived value strongly guide shopping tourism research. To provide a compressed and theoretically based discussion of luxury shopping tourism, this research is based on the concept of the extended self. The notion of self-concept has its tradition in guiding luxury consumption due to the fact that the acquisition of possessions is a form of the "extended self"; any sort of consumption is more than displaying one's status and is related to creating an "extended self" by incorporating the symbolic meaning of the object into consumption (Belk, 1988). As luxury is a socially constructed concept, its meaning is highly associated with the idea of the self in terms of exploring the deep meaning that people attach to luxury goods (Wu, Chaney, Chen, Nguyen, \& Melewar ., 2015; Christodoulides, Michaelidou, \& Li , 2009). Tourism scholars have utilised selfconcept to explore tourists' deep reasons for selecting a tourism experience (e.g., Beerli, Meneses, \& Gil ., 2007). However only limited research has applied this idea to luxury shopping (Hung et al., 2018), in particular to exploring how this formation of the self through luxury goods is related to people's holiday experiences overseas.

The sense of self is influenced by many factors, especially gender and age (Belk, 1988). The understanding of luxury shopping is strongly associated with personal features (Jap, 2010). However, previous research has often treated the Chinese as a homogeneous group without considering social demographics and gender differences in understanding luxury consumption. The study focuses on the luxury shopping behaviour of post-90s female Chinese tourists. The post-90s generation were born between 1990 and 1999, and are seen as the next engine of travel consumption (Crtrip, 2018; Bann, Luan, Poh, \& Zipser , 2017).

The study provides compressed but also focused inquiries to explore how the concept of the self influences post-90s female Chinese tourists' shopping consumption while on holiday and how this luxury shopping experience influences their concept of the self. The study contributes to understanding the subtle differences between shopping at home and shopping during overseas holiday. By linking with self-concept, the study will enlighten the very social psychological nature of luxury shopping behaviour among tourists, which depends not only on what they buy and where they buy but also on why they buy and how this buying of luxury goods links with their sense of self during their holidays. Through answering these questions, the study will further explore why luxury shopping is important for Chinese tourists.

\section{LITERATURE REVIEW}




\section{Self- concept, the extended self and luxury shopping}

Self-concept is a multidimensional construct that is commonly used to explore social psychological features behind motivation in order to gain deeper understandings (Wu et al., 2015). It denotes the totality of an individual's thoughts and feelings with reference to himself/herself as an object (Sirgy, 1982). Self-concept is related to self-perception and self-identity. It is not only related to the physical self but also the products and services consumed, and the people with whom that individual associates.

A growing trend lies in the symbolic dimension of self-concept; that is, the purchasing, display and consumption of goods and services communicate symbolic meaning to individuals and others. Individuals' behaviour will therefore be directed towards enhancing self-concept through the consumption of goods/service as symbols (Grubb \& Grathwohl, 1967). The symbolic dimension of self-concept therefore highlights the way in which individuals' identities are expressed through their selection of goods/services, which convey certain symbolic messages (Han, Nguyen \& Simkim, 2016). The success of today's businesses, especially for the younger audience, lies in their ability to satisfy varied symbolic needs (Tangsupwattana, \& Liu, 2018).

Establishing its conceptualisation based on self-concept and material processions, Belk's (1988) notion of the extended self provides valuable insights into understanding the self and symbolic consumption. Furthermore, Belk (1988) also emphasised how valued material processions can be viewed as an indication of the self, which signifies that the extended self can be seen or valued by external objects or personal possessions. As it concluded, the concept of the extended self suggests that people regard their possessions as part of themselves. These possessions are not limited to physical goods, but can include places, people, body parts and so on. It is the self-conceptualisation of possessions that lies at the heart of the extended self (Belk, 1988). The notion of the extended self is a metaphor that helps us to understand that a person's identity is not purely about "me" (the self), but also what is seen as "mine". This is particularly true in the luxury shopping context. Individuals often accumulate appropriate symbols to express their new and ideal self (Ahuvia, 2005).

People who engage in this sort of conspicuous consumption often do so to emulate the consumption patterns of the people who are directly above them in the societal hierarchy or who have the status of their ideal self (Ahuvia, 2005; Hung, 2018; Mason, 1998). This is because to some degree there is still an association between income and purchase expenditure (Husic \& Cicic, 2009). The emotional and affective experience embedded within luxury shopping therefore plays an important role. Luxury goods/services shopping experiences become the extended self and create symbolic meanings to depict a preferred view of oneself to the self and others (Wu et al., 2015; Tangsupwattana, \& Liu, 2018). For many, the exclusivity and sometimes limited edition with a high price provides a way to impress others; such an impressive function in turn enhances the self-esteem of individuals as they are viewed as special (Vigneron \& Johnson, 1999).

In order to gain an identity, individuals process their identity construction through extending the self via a continuously expanding set of things (e.g., luxury goods/services) which are regarded as one's own by the self and others (Belk, 1988). This is even more relevant in categories that involve hedonic consumption, like fashion, where symbolic 
meanings play a crucial role in the decision-making process. The process of identity construction through possessions is therefore a continuous negotiation between the self and others. The growing literature on luxury consumption and the extended self has recently moved from a general discussion of big segments (Chinese) to more specific segments (e.g., females) (Wu, Chen, \& Nguyen , 2015). A key question that has guided this movement is, "why do individuals incorporate possessions into the extended self" (Sivadas \& Venkatesh, 1995;410).

While the concept of the extended self has guided consumption research, especially luxury shopping research in marketing, the adaptation of this concept in the tourism and hospitality field is still at a developing stage (Hung et al., 2018). A few studies have started to explore how the concept of the extended self influences tourists' choice of destinations, hotels and festivals (e.g., Gration, Raciti, \& Arcodia, 2011). In acknowledging the gender and age differences in understanding the sense of self (Belk, 1988) and providing a more specific and focused understanding of how individuals incorporate possessions into the extended self (Wu et al., 2015) while travelling overseas, this research explores the deeper reasons for why post-90s Chinese female tourists travel overseas and how this is influenced by their conceptualisation of the self?

\section{The Chinese self and post-90s female tourists}

Existing studies have highlighted how cultural attributes and values influence shopping behaviour (Jin et al., 2017). The Chinese are "interdependent individuals"; individuals are defined by their relationship with others, which is different from the independent self of Western people (Hwang, 2000; Li \& Lu, 2016). Hence, conform with others and gift-giving motivate Chinese tourists' intention to purchase luxury goods and services while on holiday (e.g., Correia et al., 2018; Hung, 2018). Unlike previous research, the present study links the idea of the interdependent Chinese self and considers luxury consumption as part of the "extended self" (Belk, 1988) to explore the deep meaning behind luxury consumption during overseas holidays.

Moreover, the sense of self is often distinctive about gender and age (Belk, 1988). This is because self-perceived identities are always in the process of developing; the continuous assessment of one's own overall worth is highly associated with gender, the social-cultural environment and relationships with peers (Harter 1999). This study is particularly focused on post-90s female tourists and response the call for non-western context gender research (Yang, Yang, \& Khoo-lattimore ., 2019). This generational approach highlights that social-economic changes in the wider environment play an essential role in shifting generational values and behaviours (Chung, Chen, \& Liu , 2016). The post-1990s Chinese were born between 1990 and 1999, are seen as the next engine of consumption and are direct beneficiaries of China's economic reform and opening up policy; this makes them a distinctive generation compared with previous generations (Bann et al., 2017). Recent outbound Chinese tourism reports agree that the post-90s generation represents the future of the Chinese tourism market. They feature outstanding consumption power, especially female tourists; they account for $20 \%$ of outbound travellers; and their growth rate is the fastest among all previous generations (e.g., Ctrip, 2018). Together with the post20-00s, the youth market accounted for nearly $40 \%$ of overall Chinese outbound tourists in 2018 (Chinese Herald, 2018). Similarly, a report on luxury consumption depicts the same trend; the younger generation, the post-90s, have 
become the key market for luxury consumption (McKinsey, 2019). However, academic research has paid little attention to this emerging market. To fill this gap, this research is focused on post-90s female tourism and their overseas luxury consumption.

\section{METHODS}

To explore the deep meaning behind the luxury consumption among post-90s Chinese female tourists during overseas holidays, this study adopted a qualitative and interpretive approach. Semi-structured in-depth interviews were adopted for the data collection. This approach enabled the researchers to explore the topic broadly but with some structure to ensure that the interview questions were relevant to the research question (Denzin \& Lincoln, 1994). The interview questions were designed around the following themes: 1) luxury shopping consumption; 2) luxury shopping consumption during travel; 3) recalling their most recent shopping experience while on holiday; and 4) representation of the self and possessions.

22 interviews with post-90s Chinese females were carried out between May and October 2019. The participants were recruited first through authors' social networks. Snowball sampling was then utilised to further identify potential participants. The researchers terminated the data collection when it was apparent that the information being gathered was highly repetitive (Denzin \& Lincoln, 1994). All of the interviews were conducted in Mandarin by the native authors virtually via WeChat. The average duration of the interviews was 40 mins. As shown in Table 1, the sample was diverse in nature.

\section{Table 1}

All the data were transcribed verbatim in Chinese to ensure transcripts capture the original meanings. The data from the interviews were analysed following a qualitative inductive approach, which requires in-depth exploration of the data over a not particularly large sample (Denzin \& Lincoln, 1994). Following the constructivist grounded theory methodology, the data were analysed in three steps: open coding, axial coding and selective coding. The data analysis was first conducted independently and then cross-checked by all the Chinese authors. The themes were further confirmed through recognising the different theoretical sensitivities of the authors during the coding verification stage.

\section{FINDINGS}

\section{Luxury shopping during overseas holidays and the self}

It is noticeable that materialism, the desire for social class, and conformity with others were frequently mentioned reasons behind luxury shopping either at home or while travelling overseas. Those results are like previous studies (e.g., Correia et al., 2018). However, this qualitative inquiry found that luxury shopping during overseas holidays has some subtle differences from luxury shopping in China, as the conceptualisation of luxury is highly context-based (Christodoulides et al., 2009). Through linking with the concept of the "extended self" (Belk, 1988), luxury goods purchased overseas have become uniquely different from those purchased at home as they represent a different self, as illustrated in Table 2 below: 


\section{Table 2}

As shown in table 2, price and a happy self, exclusivity and symbols of overseas holiday experiences were found to be important motivational factors linked with materialism, conformity and social class. As shown in Table 2, among all of our participants, a reasonable price and happy self were acknowledged as a key factor for them while shopping for luxury goods abroad. Value for money was highlighted as being a reasonable price for high value goods outside of China becomes a smart and natural activity for those tourists. This explains why Chinese tourists are willing to spend three times more (Bain \& Company, 2017) when they are purchasing luxury goods abroad. All participants agree that "the luxury products are much cheaper anywhere outside of China". One said, "I am very busy. Holiday is the only time I can go shopping. It's cheap. Why not?" (P9). A reasonable price and a happy self motivate post-90s females to shop overseas. It is commonly agreed that luxury shopping represents a materialist culture and assume possessions are essential to improve people's life satisfaction and well-being (Richins \& Dawson, 1992). Tourism is all about hedonism and having fun. For most participants, "travelling and shopping always together. They make me happy"(P21). Also, "shopping is in women's nature. Appreciating the beauty will make me happy; especially when those beauties are much cheaper than in China. I feel I made a fortune. Feel I won, it makes me a very happy woman." (P4).

While all of the participants mentioned price and a happy self to an extent, their constructions of the self were slightly different, as shown in Table 2. It is noticeable that those participants whose belonged to an affluent class tended to have a different self compared with those who were in a relatively lower class. For many, luxury shopping was a type of conspicuous consumption, which could offer self-esteem; people engaged in luxury consumption to emulate the consumption patterns of the people who were directly above them in the societal hierarchy (Ahuvia, 2005). Hence, those in relatively lower social classes tended to conceptualise luxury shopping as an affordable way to acquire a higher social class. For example, P18 said "On average, for a 2000 pound handbag they can normally save around 40\% -60\% compared with the price in China. Because of the affordable price, I can afford a much more expensive handbag overseas...this will make me special." Those in an affluent classes (see Table 1 \& 2) tended to conceptualise a different self. P3 said, "I like shopping abroad, it is cheaper. Then I can prove to my husband I am a money saver not a spender". Also, P8 said, "I can afford those products in China. But I take extra efforts to fly to Europe and buy them. A wise woman like me makes the wise decision." Here, the tourism experience has become a bonus and a smart decision for those participants, who make luxury shopping a priority.

As shown in Table 2, the idea of exclusivity was highlighted as a motivation for post-90s females to purchase luxury goods abroad, as shown below:.

Every time I go to Europe, I will spent a lot of time finding limited editions that are only available in Europe not in China. Those special designs somehow are much more beautiful than those basic items that are available everywhere. They also reflect my lifestyle as a well-travelled person. When I carry it around, people know I am special. (P12). 
Here, handbags are obvious and valuable symbols. More importantly, the exclusivity of the "limited editions that are only available in Europe not in China" provides a way to impress others and in turn enhance the self-esteem of individuals (Vigneron \& Johnson, 1999). The ability to purchase a limited edition while travelling further enhanced P12's conceptualisation of herself. It was noticeable that while all of the participants agreed that many Asian shopping destinations like Singapore could offer luxury shopping experiences, it was the experience of shopping for luxury products in Western countries like the USA and Europe that made them feel that the product was more exclusive.

Luxury shopping was clearly a favourable activity among the participants and most of them tended to build close relationships between luxury shopping and the travelling self. Here, luxury shopping was full of enjoyment and an elevator of fun in terms of the destination experience. Luxury products had also become signs that reminded them of their destination experience with a slightly different focus:

The meaning of travel for me is shopping. People travel to experience novel places and products. Luxury products are a way to view the world. Those designed and branded products are a way to demonstrate Western culture and a way to expose myself as somebody who has a taste for the beauty of the culture (P7).

Buying luxury branded handbags in Paris makes me feel I live like a French lady. Fun and authentic experience. The design might be similar but it is a very different experience to purchasing them in Shenzhen...... when the bag is on my hand, my memory follows and I behave more elegantly. (P16).

As shown in Table 2, it was found that P7's material affluent is associated with western brand and culture (Alden, Jan-Benedict, \& Steenkamp, 1999). This influences her conceptualisation of self through luxury shopping. For P7, luxury shopping had become " $a$ way to expose myself as somebody who has a taste for the beauty of the culture". P16 was slightly different. People have a desire to belong to a desired group (Zhang, Pearce, \& Chen , 2019). Here, luxury goods had become a symbol that made P16 feel "like a French lady". This conformity with the locals indicates the participants" desire to taste the locals' lifestyle and culture through possessions.

\section{Self-expression in social life}

Shopping is a social activity. People engage in conspicuous consumption like luxury shopping, often believing that possessions can be a way to express themselves, especially to express their social status (Ahuvia, 2005; Wu et al., 2015). Hence, the notion of others is always influential for post-1990s tourists. When asking when and how they started their luxury consumption, friends and relatives were mentioned to express their desire to belong to a group. Some quotations are shown below:

The first luxury handbag I had was a gift from my father, a LV handbag. I have no idea about luxury products. But I know it was expensive. I feel all my friends envy me.... It becomes a habit and most of my friends are the same (P3). 
I went to an outlet with my friends during a trip in Paris. I am not familiar with those brands. They introduced me and made me feel if I could afford one of them. I somehow became a better person. If not, I would be out of fashion and out of their circle (P15).

The process from unknown to known is described by $\mathrm{P} 3$ and $\mathrm{P} 15$. While their initial experiences may have varied, the emotional feelings of "envy" and being "out of their circle" clearly demonstrate the role that others play in luxury consumption. Similarly, as the majority of Chinese tourists travel in groups, many participants, like P15, expressed that friends' behaviour and curiosity about luxury products in destinations often motivated them to make their initial purchase. P1 added, "when attending school meetings with my child with other parents, I feel I must have a luxury bag. Otherwise they will look down on my child." The Chinese are "interdependent individuals" (Hwang, 2000). For P1, the fundamental reason to have a luxury handbag was to show to others. Here, P1 was the extended self of her son (Belk, 1988). Her handbag had become an expressive symbol of her social status and thus influenced her son's image among the teachers and other children. Clearly, this desire to have an ideal image among others (friends, relatives and school teachers) plays a heavy role in post-90s females' ideal self (Sirgy, 1982). As expressed by P15, "somehow I'm a better person". Many of them also expressed their opinion about counterfeit luxury product. For example, P13, who said "I can have counterfeit clothes, but never with handbags, it's so obvious". As explained by Ahuvia (2005), sometimes it is the disposition rather than the accumulation of a possession that is influential in one's self identity. Using counterfeit handbags was considered as incongruent with her desired self-concept. Again, "it's so obvious" mattered to her identity here.

\section{Conforming with others or with the self?}

A few studies focused on Chinese tourists' shopping behaviour have one important and consistent argument: conforming with others enacts Chinese tourists' intention to purchase luxury goods and services (e.g., Correia et al., 2018; Wu, Pearce, \& Li , 2018). However, the generational cohort approach adopted here reveals a revolutionary change and that the participants had started to focus on individuality rather than conforming with others. Some examples are shown below:

Buying luxury branded products is very personal. It's my handbag. I do not want to look like everyone else. If you have a Chanel and you take the bus to work. People will still think you have a fake Chanel you brought on Taobao. I always avoid big logs and share with those who understand (P11).

I know I have many limited edition items. When I shop, I feel happy... especially when I was in early 20s. Now, life remains the same for me. Houses and cars might show our social status in a more tangible way. But handbags have become my daily routine. When you get used to it, you won't change your habits. (P3).

The post-90s Chinese are a generation that have directly experienced the benefits of 
the booming economy of China. Quite a few participants, especially those who lived in mega-cities or had an affluent lifestyle, had started to take a critical view towards luxury shopping and desired a more intrinsic meaning in life. As shown above, participants still care about the notion of others but they have moved from wishing to impress others to a niche scale and desire a unique and stylish identity.

Clearly, for the post-90s generation, their consumption focuses on products that can reflect their individuality and personal taste (Qiu \& Lin, 2013). For some, "Western culture and its luxury brands are not strangers to Chinese any more compared to previous generations" (P2). In fact, some viewed luxury products as only a small part of one's preferred lifestyle. To have a high social class and the associated identity, a bag is never enough (see P11 quotation above). For P11, those who use a handbag to claim their identity or ideal self do not yet understand the core of luxury lifestyle. Similarly, P19 said, "shopping abroad is part of my travel plan. It is an important part. But the hotel I live in, the restaurants I go to, also reflect my lifestyle and identity".

Because of the transformation from conforming with others to showing the sense of self, many of them emphasised that "luxury shopping tourism experience is a personal thing". Hence, unlike previous research, the needs to share conspicuous consumption through social media channels was less favoured by these post-90s females (e.g., Correia, et al., 2018; Wu et al. 2016). For example, P16 said, "family education taught me I need to keep a low key. Those who know you, know you". P10 said, "I will share it with a close group of friends. If you share with social media, you are showing off"." These findings demonstrate that the so-called 'conforming with others' is not only context-specific but also generation-specific. Luxury shopping tourism is still a social activity, but for post90s Chinese female tourists, their experience has become more personal and individually focused.

\section{CONCLUSION}

Shopping is an integral part of tourism, but the lack of a theoretical foundation is a notable problem within the body of tourists' shopping knowledge (Jin et al., 2017). To contribute to the advancement of this area, the current research focused on adopting selfconcepts and the extended self to explore post-90s Chinese female tourists' luxury shopping behaviour.

Theoretically, in linking the extended self (Belk, 1988) with luxury shopping tourism, the study enlightens the very social psychological nature of luxury shopping, which depends not only on what they buy and where they buy but also on why they buy and how this buying of luxury goods links with their sense of self during their holidays. Three themes were identified: luxury shopping during overseas holidays and self, selfexpression in social life and conforming with others or with the self. Through these three themes, the study shows how different selves are associated with luxury shopping overseas. It thus provides empirical evidence regarding the reasons behind their motivation, especially for shopping overseas in order to get a good price, and an exclusive and enjoyable luxury shopping experience abroad. Practically, those findings could be useful for luxury brands, as individuals may conceptualise the self differently. For the affluent class, they need to focus on a smart decision rather than a cheap price. Also, offering different products in China and in Western countries is deemed to be an appropriate measure. The desire to acquire a culturally related luxury goods becomes an 
emerging trend. The study further demonstrates what those luxury products mean to them during their social life back in China and further discusses the distinctiveness of the post90s market. It thus provides a complete picture of why the luxury shopping is important for post-90s tourists.

Furthermore, previous research tends to treat Chinese tourists as a homogeneous group, as its focus is on cultural differences and value (e.g., Hung et al., 2018). As the sense of self is often distinctive in terms of gender and age (Belk, 1988), the current research focused on post-90s Chinese female travellers: an emerging market for outbound tourism and luxury consumption. An important finding that has both theoretical and practical implications is the growing individuality. While conforming with others enacts Chinese tourists' intentions to purchase luxury goods and services (e.g., Correia et al., 2018), the current study shows an evolutional process of focusing more on individuality. This is because the post-90s generation have directly experienced the benefits of China's economic progression, open door policy and information accessibility etc. It was found that curiosity about buying luxury products is viewed as less favoured and more focused and logical shopping will be a future trend. Practically, for the luxury brands, this emerging trend is worth noting and more tailor-made promotional messages should be designed to highlight the post-90s' desire to be unique and outstanding. Luxury shopping indeed is becoming a more personal and private activity.

A few limitations of the study should also be acknowledged. First, following Belk's (1998) idea regarding the gender and age distinction in terms of the sense of self, the study only considered post-90s females. It would be interesting to use concepts such as social identity to look at the luxury shopping experience from a social/national identity perspective. Second, the qualitative approach has traditionally been criticised for its smaller sample, but in-depth understanding. A big and quantitative approach might be able to test the current findings to obtain a more holistic picture of self-concept and luxury shopping tourism in China.

\section{References}

Alden, D. L., Jan-Benedict, E. M., \& Steenkamp, R. B., (1999), Brand Positioning through Advertising in Asia, North America, and Europe: The Role of Global Consumer Culture, Journal of Marketing, 63 (1), 75-87.

Ahuvia , A.C. (2005), Beyond the extended self: loved objects and consumers' identity narratives, Journal of Consumer Research, 32, 171-184

Baan, W., Luan, L., Poh, F., \& Zipser, D. (2017), Double-clicking on the Chinese Consumer - The new health craze, the rise of the post-90s generation, and other trends worth watching, 2017 China Consumer Report, McKinsey \& Company

Bain \& Company (2017). Luxury goods worldwide market study 2017, Available at https://www.bain.com/insights/luxury-report/

Belk, R. W. (1984), "Three scales to measure constructs related to materialism: reliability, validity, and relationships to measures of happiness", in NA - Advances in Consumer Research, 11, eds, Thoms C, Kinnear, Provo, UT: Association for Consumer Research, 291-297.

Belk, R. W. (1988), "Possessions and the extended self", Journal of Consumer Research, $15,139-168$. 
Beerli, A., Meneses, G. D., \& Gil, S. M. (2007). Self-congruity and destination choice. Annals of Tourism Research, 34(3), 571-587.

Chiang, Y.-J. (2015), "Entrepreneurship of the post-90s generation (in Chinese)", China Times, Available at http://www.chinatimes.com/newspapers/20150327000329260204, Assessed date: 20 Nov, 2018.

Chung, J., Chen, C., \& Lin, Y. (2016). Cross-Strait tourism and generational cohorts. Journal of Travel Research, 55(6), 813-826.

Christodoulides, G., Michaelidou, N., \& Li, C. H. (2009). Measuring perceived brand luxury: an evaluation of the BLI scale. Journal of Brand Management, 16(5), 395-405.

Correia, A., Kozak, M., \& Kim, S. (2018). Luxury shopping orientations of mainland Chinese tourists in Hong Kong: Their shopping destination. Tourism Economics, 24(1), 92-108.

Ctrip issues - Chinese Cross-border Travel Consumption Report, (2018), China Travel News, Available at https://www.chinatravelnews.com/article/125781, Assess date: 23 Nov2018

Chinese Herald (2018). Post-90s and Post-00s becomes the key market of outbound travel consumption. Available at https://www.chinesenzherald.co.nz/news/travel/report-of-chinese-outbound-travel/

Denzin, N., \& Lincoln, Y.S. (1994), The SAGE Handbook of Qualitative Research, London: SAGE.

Gazley, A., \& Watling, L., (2015), Me, My Tourist-Self, and I: The Symbolic Consumption of Travel, Journal of Travel and Tourism Marketing, 32(6), 639-655.

Grubb, E.L. \& Grathwohl (1967). Consumer self concept, symbolism and market behavior: a theoretical approach. Journal of Marketing, 31 (4), 22-27

Gration, D., Raciti, M., \& Arcodia, C. (2011). The role of consumer self-concept in marketing festivals. Journal of Travel \& Tourism Marketing, 28(6), 644-655.

Han, S.H., Nguyen, B. and Simkim, L. (2016), "The dynamic models of consumers' symbolic needs: in the context of restaurant brands", European Journal of Marketing, 50 (7/8), 1348-1376.

Harter, S. (1999). The construction of the self: A developmental perspective. Guilford Press.

Husic, M. and Cicic, M. (2009), "Luxury consumption factors”, Journal of Fashion Marketing and Management, 13 (2), 231-245.

Hung, K., Qiu Zhang, H., Guillet, B. D., \& Wang, L. (2018). China watching: luxury consumption and its implications. Journal of Travel \& Tourism Marketing, 1-16.

Hung, K. (2018). Consumption of Luxury Hotel Experience in Contemporary China: Causality Model for Conspicuous Consumption. Tourism Review, 22(3-4), 171-185

Hwang, K. K. (2000). Chinese relationalism: Theoretical construction and methodological considerations. Journal for the Theory of Social Behavior, 30 (2), 155178

Jap, W. (2010). Confucius face culture on Chinese consumer consumption values toward Global Brands. Journal of International Management Studies, 5(1), 183-192

Jin, H., Moscardo, G., \& Murphy, L. (2017), Making sense of tourist shopping research: A critical review, Tourism Management, 62, 120-134.

Li, J., \& Lu, Y. (2016). Chinese culture in tourist research: a review and comparison of Chinese and English studies in 1993-2012. Tourism Review, 71(2), 118-134. 
Mason , R.S., (1998) Conspicuous consumption: a study of exceptional consumer behaviour, St martin's press, NY, USA

McKinsey (2019). Chinese luxury consumption report 2019. Available at https://www.mckinsey.com.cn/wp-content/uploads/2019/04/McKinsey-China-LuxuryReport-2019-Chinese.pdf

Qiu, J., \& Lin, R., (2013), New Trends among Young Chinese Consumers, SERI Quarterly, 6(1), 23-31.

Richins, M. \& Dawson, S., (1992), A Consumer Values Orientation for Materialism and Its Measurement: Scale Development and Validation, Journal of Consumer Research, 19 (3), 303-316.

Sirgy, M. J., (1982), Self-Concept in Consumer Behavior: A Critical Review, Journal of Consumer Research, 9 (3), 287-300.

Sivadas, E., \& Venkatesh, R., (1995), “An Examination of Individual and Object-Specific Influences on the Extended Self and Its Relation to Attachment and Satisfaction", in NA - Advance in Consumer Rsearch, 22, eds, Frank, R. Karde and Mita, Sujan, Provo, UT: Association for Consumer Research, 406-412.

Tangsupwattana, W., \& Liu, X. (2018). Effect of emotional experience on symbolic consumption in Generation Y consumers. Marketing Intelligence \& Planning, 36(5), 514-527.

Travel Weekly China (2019). 2018 outbound tourism big data report. [Online] Available at https://www.travelweekly-china.com/73800, Accessed date: 6 March 2019.

Vigneron, F. and Johnson, L. W. (1999), "A review and a conceptual framework of prestige-seeking consumer behavior”, Academy of Marketing Science Review, 1999 (1), 1-15.

Wu, M. Y., Pearce, P. L., \& Li, Q. (2018). Chinese behind the wheel: Factors affecting their satisfaction with international self-drive holidays. Journal of Destination Marketing \& Management, 9, 12-19.

Wu, M.S.S., Chaney, I., Chen, C.H.S., Nguyen, B., and Melewar, T.C. (2015), "Luxury Fashion Brands: Factors Influencing Young Female Consumers' Luxury Fashion Purchasing in Taiwan", Qualitative Market Research: An International Journal, 18 (3), 298-319.

Wu, M.S.S., Chen, C.H.S., \& Nguyen, B. (2015), Luxury brand purchases and the extended self, Asia-Pacific Journal of Business Administration, 7(3), 153-173.

Yang, E. C. L., Yang, M. J. H., \& Khoo-Lattimore, C. (2019). The meanings of solo travel for Asian women. Tourism Review.

Zhang, C. X., Pearce, P., \& Chen, G. (2019). Not losing our collective face: Social identity and Chinese tourists' reflections on uncivilised behaviour. Tourism Management, 73, 71-82. 